\title{
Inovação no setor público: uma análise do choque de gestão (2003-10) sob a ótica dos servidores e dos preceitos teóricos relacionados à inovação no setor público*
}

\author{
Roberta Graziella Mendes Queiroz** \\ Ivan Beck Ckagnazaroff***
}

SumÁrio: 1. Introdução; 2. Mudança organizacional no setor público; 3. Inovação no setor público brasileiro: dimensões gerenciais e democráticas; 4. Conclusão.

Summary: 1. Introduction; 2. Organizational change in the public sector; 3. Innovation in the Brazilian public sector: managerial and democratic dimensions; 4. Conclusion.

Palavras-chave: mudança organizacional; choque de gestão; inovação no setor público; modernização da administração pública.

KEYWORDs: organizational change, managerial shock; innovation in the public sector; public administration modernization.

Este artigo - de cunho qualitativo e abordagem interpretacionista - analisa o choque de gestão (CG), política de governo do estado de Minas Gerais iniciada

\footnotetext{
* Artigo recebido em nov. 2009 e aceito em mar. 2010.

** Mestre em administração pela Universidade Federal de Minas Gerais (UFMG). Pós-graduada em gestão pública de transportes e obras pela Escola de Governo Professor Paulo Neves de Carvalho (EG/Fundação João Pinheiro). Administradora pública pela Escola de Governo Professor Paulo Neves de Carvalho (EG/Fundação João Pinheiro). Atualmente ocupa o cargo de especialista em Políticas Públicas e Gestão Governamental pela Secretaria de Planejamento e Gestão do Estado de Minas Gerais (Seplag). Endereço: Rua Tomaz Gonzaga, 686 — Lourdes - CEP 30180-140, Belo Horizonte, MG, Brasil. E-mail: robertamqueiroz@yahoo.com.br.

$* * *$ Doutor em Doctoral Programme Aston Business School pela Aston University. Mestre em administração pela Universidade Federal de Minas Gerais. Economista pela Pontifícia Universidade Católica de Minas Gerais. Professor adjunto da Universidade Federal de Minas Gerais, pesquisador do Conselho Nacional de Desenvolvimento Científico e Tecnológico, colaborador da Universidade Federal de Viçosa. Endereço: Avenida Antônio Carlos, 6627, sala 4036 - Pampulha CEP 31270-901, Belo Horizonte, MG, Brasil. E-mail: ivanbeck@face.ufmg.br.
} 
em 2003 e com metas previstas até 2023. O principal objetivo foi verificar em que medida o modelo de gestão mineiro inovou tendo em vista duas perspectivas: a opinião dos atores envolvidos na construção, implementação e avaliação do CG, e os preceitos teóricos da inovação no setor público. O quadro teórico de referência levou em consideração as abordagens e perspectivas da mudança organizacional, enfatizando a realidade da inovação na administração pública brasileira. Ao todo, 70 servidores públicos submeteram-se a entrevistas semiestruturadas e tiveram suas percepções coletadas e estudadas. Dos resultados observados, pôde-se averiguar que o choque foi uma mudança de cunho estritamente gerencial, que inovou em termos estratégico, tecnológico, estrutural e de controle; não obtendo o mesmo êxito em relação às dimensões humana, cultural e política da mudança.

Innovation in the public sector: an analysis of the managerial shock (2003-10) from the perspective of public workers and the theoretical guidelines

This article is a qualitative work with an interpretative approach about the managerial shock, a policy adopted in 2003 by the Minas Gerais state government which has been projected to reach its goals by 2023. The main purpose of this study was to verify how innovative such management model is, taking into account two perspectives: the opinion of the stakeholders involved in developing, implementing and evaluating the model, and the theoretical principles related to innovation in the public sector. The theoretical framework included the approaches and perspectives of organizational change, emphasizing the current state of innovation in the Brazilian public administration. Seventy state workers were submitted to a semi-structured survey and had their perceptions collected and analyzed. The results revealed that the managerial shock was considered a strictly managerial change, which innovated in the strategic, technological, structural and control aspects, but it did not reach the same success in relation to human, cultural and political change.

\section{Introdução}

Na tentativa de romper com problemas de gestão advindos de governos anteriores, dá-se início, em 2003, a um processo de mudanças na administração pública do estado de Minas Gerais. Naquele ano, mediante um déficit aproximado de $\mathrm{R} \$ 2,4$ bilhões, agravado por um cenário caótico de precários serviços públicos e infraestrutura, bem como de dificuldades relativas à arrecadação de recursos e de cumprimento das obrigações estatais, o governo mineiro apresentou o choque de gestão (CG), como uma alternativa à necessária superação do quadro econômico, fiscal e administrativo-institucional vigente à época.

Traduzido como um aglomerado de iniciativas de impacto, o CG teve como principal objetivo impulsionar a administração pública estadual a assumir novos padrões comportamentais e a se posicionar de maneira mais agres- 
siva em busca de eficiência e eficácia. O objetivo almejado com a consolidação da política, que se estendeu por duas fases (2003-2006 e 2007-2010, ainda em vigor), era o de, numa perspectiva temporal de longo prazo, transformar Minas Gerais no melhor estado brasileiro para se viver. Para tanto, novos modelos de gestão e a modernização do aparato institucional foram propostos.

Juntamente com as iniciativas de cunho gerencial, a estratégia do choque de gestão priorizou, em sua concepção, a construção de uma única agenda, que levasse em consideração tanto os parâmetros econômicos e fiscais como as questões sociais, e fundamentou-se a partir da perspectiva de governança social (equilíbrio e articulação de interesses entre Estado, mercado e sociedade).

Por essas e outras razões, os idealizadores da política a identificaram como uma proposta inovadora. Para esses atores, o modelo de gestão mineiro, além de ter se caracterizado como uma iniciativa ousada, distinguiu-se de quaisquer outras reformas administrativas ocorridas no país e no exterior.

Cabe lembrar, contudo, que o fato de os proponentes da política defenderem o caráter inovador da mesma, não necessariamente faz com que exista um consenso sobre a questão; uma vez que o entendimento de determinados atores sobre um mesmo processo pode variar de maneira significativa, fazendo com que uma parte das pessoas opine favoravelmente, reconhecendo algo como inovador; e outra parcela apresente argumentações completamente contrárias. Foi a partir dessa premissa que este artigo se desenvolveu. O caminho adotado deu voz aos diversos atores envolvidos com o modelo de gestão mineiro, partindo-se dos servidores executores da política e indo até aqueles que a formularam.

A tentativa de se compreender a percepção dos servidores públicos estaduais sobre o choque de gestão como experiência inovadora fortaleceu a crença de que tais atores deveriam ser reconhecidos como sujeitos com visões singulares, especialmente no tocante à sua existência dentro da organização, à presença da organização na sua vida e aos significados, por eles atribuídos, às transformações ocorridas.

Este artigo procura entender o choque de gestão sob a ótica dos servidores, inseridos no contexto da política e, a partir disso, analisar o modelo com base nos preceitos teóricos que subsidiam as discussões sobre o tema "inovação no setor público".

\section{Mudança organizacional no setor público}

Significativas intervenções no setor público ocorrem por meio das chamadas reformas ou modernizações administrativas. De acordo com Souza (1994), 
a grande questão a ser discutida no caso da área pública é se essas reformas podem de fato ser compreendidas como mudança organizacional. Para o autor, baseando-se nos argumentos de Bertero (1976), a mudança encontra-se sempre aliada ao processo decisório e se desenvolve a partir de duas perspectivas que devem ser complementares: de um lado a alteração na estrutura e de outro as modificações de cunho comportamental.

Com base nessas premissas, ele sugere que "qualquer decisão por reformar ou modernizar o Estado conduz sim, necessariamente, a uma mudança na organização". Nesse sentido, o desafio proposto para o setor público passa a ser, segundo o autor, o de promover mudanças que abranjam ao mesmo tempo as diversidades internas e o dinamismo organizacional, e adotem como pressuposto a relação de complementaridade existente entre estrutura e comportamento.

Outra discussão interessante sobre essa temática foi abordada por Matos (1988) na tentativa de analisar a importância de se modernizar a administração pública, considerando para tanto a diferenciação entre modernização organizacional (MO) e modernização administrativa (MA).

O conceito trazido pelo autor de modernização organizacional amparase nas concepções teóricas de mudança social. Para ele, a MO é um processo complexo que envolve dimensões políticas e educacionais, que são desenvolvidas de forma constante nas organizações sociais, com o intuito de provocar transformações nas relações de trabalho e de poder (democratização), nos custos e nos resultados organizacionais. Por outro lado, a MA apresenta-se como uma alternativa limitada de modificar a organização somente no campo estrutural, alterando normas, procedimentos e simplificando rotinas.

A partir de tais distinções, o autor argumenta que "a mudança no setor público, seja por reformas ou processos de modernização, só acontecerá de forma efetiva quando observar e colocar em prática os elementos inseridos na MO"; deixando de lado assim alternativas de mudanças meramente administrativas (normativas).

Partindo-se do pressuposto de que a mudança no setor público pode ser caracterizada como uma mudança organizacional e de que seus processos devam se inserir no contexto da MO, cabe nesta parte do estudo desenvolver uma análise mais profunda acerca dos parâmetros conceituais da mudança, considerando suas diferentes perspectivas e abordagens.

\section{Perspectivas e abordagens da mudança organizacional}

Em âmbito organizacional, a temática mudança organizacional começou a ser mais debatida em função da própria dimensão de velocidade com que as mu- 
danças vinham ocorrendo. Essa rapidez se deveu, entre outras explicações, ao desenvolvimento das tecnologias, acompanhado dos avanços da era informacional, e às demais pressões que circundaram o ambiente (questões econômicas, culturais, sociais, políticas etc.).

De acordo com Bennis (1976), uma das formas mais comuns de se constatar a mudança no mundo foi por meio da inovação tecnológica, subordinada aos avanços industriais e, principalmente, à transição dos regimes autocráticos para os democráticos.

Segundo Cavalcanti (1979), a influência da questão ambiental no processo de mudança é clara. Para a autora, quaisquer que sejam os formatos de transformação das organizações, os mesmos só terão os seus "porquês", "o que" e "como" respondidos se observarem e entenderem as modificações ambientais (valores, produtos, relações, demandas socioeconômicas, tecnologias e anseios). Weick e Quinn (1999), por sua vez, argumentaram que as mudanças nunca se iniciam, uma vez que as mesmas nunca terminam — são constantes e contínuas.

São distintos os olhares com que se compreendem os fenômenos organizacionais e consequentemente seus formatos de mudança. Para Morgan (1996), um entendimento efetivo sobre as organizações (em relação ao seu processo evolutivo - transformações ocorridas, bem como no tocante aos seus caminhos futuros - mudanças pretendidas) pode ser viabilizado por meio de abordagens metafóricas.

Nesse sentido, o autor sugere, em uma de suas leituras, um olhar organizacional subsidiado por três imagens de mudança: autopoiesis - compreensão das organizações como sistemas autorreprodutores, através dos quais as mudanças ocorrem por meio de parâmetros circulares e interativos; ideias cibernéticas - "a lógica da mudança se acha encoberta pelas tensões e tendências encontradas nas relações circulares (Morgan, 1996:241)"; mudança dialética - insere-se o estudo dos opostos, que estão imersos em um "estado de tensão que também define um estado de harmonia e totalidade (Morgan, 1996:261-262)".

Além dessas perspectivas, a mudança nas organizações ainda pode ser compreendida em função de seus aspectos mais subjetivos - culturais, estéticos, políticos, entre outros. Segundo Wood Jr. (2008), em detrimento das abordagens mais focadas, como as já mencionadas, uma análise resumida e esquemática da mudança conduziria o tema a dois campos de entendimento: a abordagem estrutural (mais direcionada "aos princípios da escola de administração clássica") e a dimensão comportamental (com "mais características da escola de relações humanas"). 
Para fins deste artigo, serão considerados como conceito e dimensões norteadoras de mudança organizacional os elementos definidos por Motta (2001). Para o autor, a mudança se define por meio de cinco diferentes paradigmas: (1) mudança como compromisso ideológico; (2) mudança como necessidade ambiental; (3) mudança como uma releitura crítica da realidade; (4) mudança como uma intencionalidade social; (5) mudança como um processo de transformação do indivíduo. Com um olhar mais sistêmico, o autor ainda analisa a mudança a partir de seis panoramas conceituais da organização: estratégico, estrutural, tecnológico, humano, cultural e político.

No primeiro deles, o panorama estratégico, que enfatiza a racionalidade, a mudança só ocorre quando há uma redefinição da missão, finalidades e formas de atuação organizacionais. Já na perspectiva estrutural, fundamentada pelo princípio da hierarquia, mudar significa alterar a distribuição formal de autoridade e responsabilidade intraorganizacional.

No campo tecnológico (divisão de trabalho, especialização e tipo de tecnologia), por sua vez, a mudança reflete modificações de cunho intelectual e material. O quarto panorama, o humano, evidencia um olhar da mudança sob o indivíduo. Assim, são as transformações produzidas nas ações, nos comportamentos e nas formas de participação do ser humano dentro da organização que representam a mudança.

A perspectiva cultural, em detrimento da anterior, direciona sua atenção para o coletivo compartilhado (grupo social ou organização), ao invés do focar o indivíduo. A mudança pretendida nessa dimensão só acontece quando há uma modificação de valores, hábitos, ritos, símbolos, linguagem, interesses comuns e crenças. No último panorama, o político, mudar significa interferir na estrutura de poder de modo a redistribuí-la e subsidiá-la a outras escolhas de ação.

E, por fim, Motta (2001) apresenta, considerando o desenvolvimento da mudança, as duas vertentes que fomentam e subsidiam a ocorrência desta - o "incrementalismo" e o "radicalismo". Segundo o autor, na vertente incremental, mudar significa introduzir pequenas alterações organizacionais (no todo ou em parte) de maneira moderada e permanente, sem tender à conformação. Já a corrente radical, explica ele, prima pelo imediatismo e pressupõe uma mudança revolucionária (de impacto no curto e longo prazos), uma ruptura com o progresso natural das organizações, na tentativa de reagir à morte ou decadência dos sistemas.

\section{A inovação no setor público vista como uma mudança radical}

A concepção de inovação encontra-se muito próxima ao conceito de mudança. Há autores que não estabelecem distinções entre as duas abordagens - como o 
próprio Motta (2001). Spink (2006) argumenta que, antes de se analisar a concepção do que vem a ser inovação na gestão pública, é preciso entender o contexto no qual a mesma se desenvolve. Esta premissa, por si só, segundo o autor, inviabiliza a existência de um consenso acerca da temática e do seu conceito.

Por outro lado, para Klering e Andrade (2006), o setor público, em função da natureza complexa de suas políticas, precisa promover inovações concretas, que conduzam a transformações efetivas. De acordo com eles, o pressuposto mais adequado para a gestão pública era o de que se associasse o conceito de inovação no setor público à perspectiva de transformação radical. Dessa maneira, Klering e Andrade (2006), agregando um sétimo panorama conceitual aos seis já apresentados por Motta (2001), definiram a inovação no setor público como: "uma mudança de cunho radical que se justifica por fins estratégico, estrutural, humano, tecnológico, cultural, político e de controle (foco em transparência e accountability)".

\section{Inovação no setor público brasileiro: dimensões gerenciais e democráticas}

Na opinião de Spink (2006), há dois tipos de abordagens, sutilmente distintas, usadas ao se analisar experiências de êxito na gestão pública. Uma delas, bem difundida, é a abordagem das melhores práticas, em que se compreende a experiência a partir de seus parâmetros de sucesso, que posteriormente acabam por se definir como padrões a ser seguidos, replicados.

A segunda abordagem, de caráter mais reflexivo e dialógico, refere-se à que identifica tais experiências inovadoras como práticas emergentes, regadas por conhecimentos tácitos ou implícitos. Na última perspectiva não existe a pretensão de se definir o melhor, mas sim entender e discutir as experiências como possibilidades de ações válidas e enriquecedoras.

O autor, com base em 100 experiências classificadas como semifinalistas no Programa Gestão Pública e Cidadania (instituído desde 1996 pela Fundação Getulio Vargas, em parceria com a Fundação Ford), realizou uma pesquisa com os gestores daquelas a fim de compreender o que eles entendiam por inovação; e para verificar em quais aspectos seus programas, projetos ou atividades inovavam em relação a experiências anteriores.

Os resultados obtidos explicavam a temática "inovação no setor público", aplicada ao contexto da gestão pública brasileira (estadual e local) e da gestão indígena, a partir dos seguintes temas: conjunto de soluções para os problemas vigentes; processo de mudança na forma de pensar a ação; pro- 
cesso novo de inclusão coletiva, a fim de desenvolver medidas de cogestão; processo de maior integração entre atores, criando mecanismos de articulação e novos arranjos institucionais com os mesmos; conjunto de ações que priorizem a "humanização" de serviços existentes a um público, antes não atingido, ou, até mesmo, a extensão de um serviço; ações novas, jamais vistas; e múltiplas temáticas.

Com base em uma perspectiva histórica, Farah (2006) faz uma leitura das inovações vivenciadas na administração pública brasileira. Para a autora, o ciclo de inovações na gestão pública do país foi iniciado no governo de Getúlio Vargas, década de 1930, com a instituição de bases para consolidação de um novo papel para o Estado, o de desenvolvimentista e de articulador da formação de uma identidade nacional.

Outro período apontado como palco de inovações na área pública brasileira foi a década de 1980, época que também priorizou a construção de novas instituições e práticas. Esses dois momentos de inovação no país, 1930 e 1980, pautaram-se não apenas na criação de coisas novas, mas também na superação de características graves advindas de tempos anteriores, relativas à própria administração da máquina pública, bem como de suas políticas (Farah, 2006).

As inovações trazidas na década de 1980 foram respostas às demandas dos movimentos sociais, no período de 1970, que pleiteavam contra: a centralização financeira e decisória na esfera federal; a perspectiva institucional fragmentada; a formulação de políticas sob a lógica clientelista; entre outros.

Paralelamente a essas dimensões democráticas da mudança ocorrida no setor público brasileiro, Farah (2006) relata que, em função do grave cenário de crise fiscal no país, a agenda de reformas, proposta na década de 1980, agregou às suas prioridades a temática gestão, dando ênfase aos fatores de empreendedorismo e eficiência. Com base nisso, de acordo com a autora, a inovação no setor público brasileiro assumiu duas direções efetivas e complementares:

- uma direcionada para a eficiência - representada pelo processo das reformas gerenciais. Os avanços de gestão no setor privado (final dos anos 1960 em países desenvolvidos) influenciaram as mudanças produzidas pelo setor público; principalmente em relação à questão da flexibilidade;

V e outra voltada para a democracia - busca pela ampliação da participação social e da descentralização dos processos de construção de políticas públicas.

Pautando-se nas discussões já apresentadas, para fins deste artigo, a inovação no setor público foi compreendida como uma mudança de caráter 
radical que se justifica por seus fins estratégico, estrutural, humano, tecnológico, cultural, político e de controle (de acordo com o conceito trazido por Klering e Andrade, 2006) e que se direciona tanto para a eficiência quanto para as dimensões mais democráticas da mudança (conforme abordado por Farah, 2006).

\section{Choque de gestão em Minas Gerais (2003-10) como perspectiva inovadora}

De acordo com Vilhena, Martins e Marini (2006), as gestões governamentais anteriores ao choque de gestão, principalmente as duas últimas (1995-98 e 1999-2002), deixaram como herança um cenário decadente de déficit fiscal, descrédito internacional e ausência de legitimidade do governo ante a sociedade e a própria máquina administrativa. As razões dadas para tanto, explicaram os autores, relacionaram-se ao fato de os governos antecedentes não terem priorizado uma gestão por resultados, diretriz adotada pelo CG.

Os autores ainda relataram que, na formulação e implementação do choque, dois aspectos foram considerados diferenciais da política de gestão se comparados a outras reformas, e justificaram, na opinião de seus formuladores, a sua originalidade:"a adequação institucional voltada para o desenvolvimento" e "a perspectiva integradora das políticas".

Ao propor a adequação institucional, a política de gestão mineira levou em consideração, segundo seus idealizadores, não somente a necessidade de se equilibrar as relações de domínio e de poder entre Estado, mercado e terceiro setor; mas principalmente de se consolidar um papel estatal mais dinâmico capaz de estabelecer interlocuções coerentes entre mercado e sociedade civil, de modo a ativar e direcionar as capacidades deles.

Outra iniciativa considerada desafiadora para o governo e apontada como inovadora na construção da estratégia proposta para Minas foi a opção pelo uso do duplo planejamento - ações voltadas do "hoje para hoje" e do "hoje para o amanhã" (Guimarães e Almeida, 2006).

Segundo Abell (1999), a finalidade do duplo planejamento ou dupla estratégia se dá na tentativa de promover a coexistência de dois planejamentos, um para o presente e outro para o futuro, associando assim duas perspectivas: de um lado, a busca pelo sucesso operacional no curto prazo e, do outro, a garantia do sucesso estratégico da organização no longo prazo.

Na visão de Guimarães e Almeida (2006), o quadro crítico herdado de períodos anteriores explicaria o porquê do CG ter escolhido a estratégia dual. 
As principais consequências trazidas de governos passados resumiram-se em falhas na construção e realização das estratégias.

Em oposição a tais falhas, os idealizadores do choque consideraram que seu planejamento estratégico, tanto na fase de construção quanto no momento de implementação, deveria levar em consideração as seguintes abordagens: envolvimento de todos os stakeholders, desde os idealizadores (responsáveis diretos) até os cidadãos, os servidores e dirigentes de órgãos; estudo de viabilidade da estratégia analisado em relação aos fatores intertemporalidade, hierarquização dos instrumentos, tempo (curto e longo prazos) e focalização de ações e metas; organização do processo orçamentário alinhando-o à estratégia.

Dividido em duas fases, a primeira, ocorrida no período de 2003 a 2006, e a segunda, proposta para o ano de 2007 a 2010, o CG apoiou-se em práticas gerenciais, na tentativa de consolidar uma gestão por resultados.

De acordo com Fabris (2007:2), a primeira geração do CG ocupou-se de racionalizar as despesas em 2003, aumentar a receita em 2004 a fim de controlar as contas públicas e possibilitar o crescimento de investimentos nos anos subsequentes, 2005 e 2006. Por sua vez, a segunda geração (2007-2010) teve como foco a agilidade e a qualidade dos gastos públicos, principalmente na área social, em busca da "equidade entre as pessoas e as diferentes regiões do Estado"; uma administração já não mais voltada para a administração de dívidas, mas sim para a gestão de resultados.

\section{Procedimentos metodológicos}

Este artigo adotou a estratégia qualitativa, tendo em vista que a natureza do objeto de pesquisa demandava uma análise de caráter interpretativo dos dados coletados. Para Richardson (1999:80), os estudos que se baseiam na metodologia qualitativa têm maior potencial para "descrever a complexidade de determinado problema, analisar a interação de certas variáveis, compreender e classificar processos dinâmicos vividos por grupos sociais".

Ao todo foram entrevistadas 70 pessoas, distribuídas entre o que se convencionou chamar de "classe executora" e "classe idealizadora" do modelo de gestão. Para a análise da visão da classe executora, foram escolhidas duas secretarias de Estado: a de Defesa Social (Seds) e a de Transportes e Obras (Setop). A partir daí, definiu-se como critério de investigação a compreensão das opiniões dos atores, que ocupavam posições hierárquicas dentro de cada órgão. Assim, foram três os grupos de servidores investigados em cada se- 
cretaria: os "subsecretários" (nível estratégico), os "superintendentes" (nível tático) e os "diretores e técnicos" (nível operacional).

Já na classe dos formuladores, optou-se por entrevistar os atores, pertencentes ou vinculados à Secretaria de Estado de Planejamento e Gestão (Seplag), que estiveram diretamente envolvidos com a construção estratégica da política, em suas duas fases.

Da classe idealizadora, foram entrevistadas quatro pessoas (dois secretários de estado, um secretário-adjunto de estado e o coordenador do Programa Estado para Resultados). Os 66 investigados restantes pertenciam à classe executora, sendo 45 da Seds (três subsecretários, sete superintendentes e 35 diretores e técnicos) e 21 da Setop (dois subsecretários, cinco superintendentes e 14 diretores e técnicos).

A análise foi dividida em três categorias. A primeira preocupou-se em entender se o CG, na opinião de todos os grupos, era de fato inovador, quando comparado a outras gestões governamentais anteriores. E, posteriormente, em averiguar quais os aspectos trazidos pela política, que a caracterizavam como inovadora. A segunda categoria, por sua vez, analisou os aspectos inovadores do choque a partir dos preceitos teóricos apresentados aqui. $\mathrm{E}$ a terceira, por fim, levou em consideração a investigação em torno das dimensões conceituais do tema inovação na gestão pública.

\section{Resultados da pesquisa}

As citações feitas aqui foram identificadas com base no grupo a que o relator pertencia, bem como na sua secretaria de origem e em um número definido em função da ordem de realização das entrevistas; exemplo diretor Seds 10. No grupo de superintendentes da Setop, que totalizou cinco servidores pesquisados, eles receberam o número identificador de 1 a 5 ; já os superintendentes da Seds, que foram sete, foram enumerados de 1 a 7 , e assim por diante.

\section{Os aspectos inovadores do choque de gestão}

Depois de descreverem um pouco a política e expressarem suas expectativas e familiaridades com a mesma, todos os atores investigados foram questionados sobre, primeiramente, o que eles entendiam por inovação; e, logo em seguida, se, com base na concepção que eles tinham, o choque de gestão poderia ser identificado como um exemplo de inovação no setor público. 
De forma quase unânime, com exceção de três opiniões, todos os servidores ouvidos, das duas classes, enfatizaram, de um modo assertivo, que a política adotada em Minas Gerais, ao longo das duas gestões governamentais (2003-2006 e 2007-2010), poderia ser considerada uma inovação. É interessante observar que, em quase todas as respostas, notou-se esse tom, de firmeza e confiabilidade, aliado a dois fatores: alta credibilidade dada à política; e grande expectativa de continuidade, como exemplificam os relatos abaixo:

\section{Classe executora (Grupos Seds-MG e Setop-MG)}

Superintendente Setop 2 - Choque de gestão é uma inovação, pois foi o conjunto de ideias que, bem organizadas, romperam essa barreira, porque permearam, mudaram a concepção do setor público. O CG foi o início e o meio de um ciclo de modernização que impactou e mudou a perspectiva do serviço público para os próximos anos.

Subsecretário Seds 2 - Com certeza, ele (o CG) melhorou as ações, melhorou o atendimento à sociedade. Ele melhorou tudo! Acho que ele inovou até o ânimo das pessoas! Melhorou em tudo! Acho que ele inovou com certeza.

Diretor Seds 2 - Com certeza, ele (o CG) é a grande inovação e a partir dele vieram todas as outras, de caráter de melhoria e de concepção de trabalho.

Diretor Setop 1 - Não tenho nenhuma dúvida disso! É uma inovação! Uma grande inovação!

Técnico Setop 5 - Com certeza, é uma inovação no setor público! Porque eu nunca vi trabalhar com metas, a gente atendia a planos, mas não com objetivos e metas a serem alcançadas.

Classe idealizadora (Grupo Seplag-MG)

Idealizador Seplag 2 - Se analisarmos pelos instrumentos, acordo de resultados, prêmio por produtividade, avaliação de desempenho, termo de parceira, monitoramento, tudo isso já existia na Constituição. Só que ninguém nunca pegou e aplicou, principalmente, de forma conjunta, para discutir a implementação de uma política pública. É inovação, pois se trouxe para dentro do governo uma prática que não era utilizada.

Idealizador Seplag $3-\mathrm{O}$ choque de gestão é inovador, com parâmetros internacionais. Internamente, no Brasil, tá ficando muito chato comparar. Minas Gerais não tinha definida uma estratégia há anos [...].

Dos três depoimentos que não caracterizaram o choque como uma inovação, um deles, feito pelo subsecretário 3 da Seds, o definiu como revolu- 
cionário e os outros dois apresentaram opiniões críticas em relação a essa política. A primeira opinião, do superintendente 2 da Seds, entendeu o CG da seguinte forma: "[...] é inovador no campo da gestão, como metodologia de acompanhamento, mas não necessariamente no campo democrático, na gestão participativa". Na entrevista, o servidor investigado demonstrou que, em termos gerenciais, ele acreditava que o modelo implementado em Minas havia inovado com relação à adoção de mecanismos de monitoramento de projetos; mas que não havia evoluído no sentido de oferecer à sociedade canais de diálogo com o estado - para ampliar sua participação na formulação, implementação e avaliação das políticas públicas. E o segundo posicionamento crítico, do superintendente 4 da Seds, argumentou que o choque de gestão fez uso de práticas já comuns, principalmente na iniciativa privada e o investigado analisou a política da seguinte forma: "CG traz novidades boas, só acho que não seja totalmente inovação, pois ele não trouxe coisas totalmente novas".

Um último destaque será dado a uma opinião em particular, que, embora tenha caracterizado o CG como inovador, trouxe em sua argumentação um olhar negativo da evolução da política. Para o entrevistado, o choque de gestão foi apenas uma resposta à necessidade de adaptação do setor público às pressões ambientais em termos econômicos, tecnológicos e institucionaladministrativos. Resposta que poderia vir a qualquer momento, independente de ser no governo do CG ou em outros governos. De acordo com a percepção desse ator, graduado em engenharia e com mais de 25 anos de serviço público, pouca preocupação (em termos de benefícios salariais) foi dispensada, pela política, aos servidores de carreira, com maior experiência na gestão pública; bem como aos servidores alocados como "função pública". Com um tom descontente, o investigado argumentou:

Técnico Setop 8 - Toda mudança é uma inovação, resta saber se é para o bem ou para o mal; toda inovação pode ser refinada, resta saber se eles vão pensar na situação do servidor. Acho que já foram longe demais com esse choque de gestão tão desumano [...].

É fato que, durante o processo de realização das entrevistas, muitas respostas expressaram argumentações favoráveis ao modelo adotado em Minas. Com base nessas opiniões, acredita-se que parte dos efeitos do choque de gestão sobre a máquina pública refletiu em mudanças importantes e, por vezes, positivas.

No entanto, não se tira o mérito de um olhar questionador e, por vezes, revoltado como o que se identificou na citação acima. Pelo contrário, esse 
olhar tem um papel fundamental para a compreensão mais apropriada da realidade. É imprescindível verificar como alguns atores se sentiram preteridos no decorrer do CG e expor suas percepções de resistência ou reivindicações. Relatos desse tipo conduzem a inferências como: o canal de comunicação e negociação entre os diferentes grupos (diretores e técnicos, superintendentes, subsecretários e idealizadores) não foi efetivo, durante a política; e as mudanças na gestão não foram seguidas de transformações necessárias, nos âmbitos organizacionais, político e cultural.

A partir da análise de todas as entrevistas, pôde-se verificar que as dimensões que caracterizaram o modelo de gestão mineiro como inovador referiram-se aos avanços percebidos, pelos atores investigados, em relação às seguintes melhorias:

v pessoais concretas - por exemplo, pagamento de salário mensal e 13ํㅜㅇ salário em dia, benefícios concedidos (tíquete alimentação e prêmio por produtividade), revisão de planos de carreira (adicional de desempenho por escolaridade), cursos de qualificação e capacitação para os servidores etc.;

- pessoais subjetivas - por exemplo, maior motivação e interesse do servidor com o trabalho, maior organização da máquina pública, maior sintonia de trabalho entre as equipes, mudança da imagem profissional do servidor etc.;

v tecnológicas e estruturais - por exemplo, inserção de novos sistemas tecnológicos (compras, logística, finanças), aquisição de equipamentos, definição de novas regras funcionais, readequação estrutural dos órgãos, e redistribuição de cargos;

v sociais concretas e subjetivas - por exemplo, criação de mecanismos para gerar transparência das ações estatais, maior ética governamental e valorização do cidadão;

v financeiras e orçamentárias - por exemplo, disponibilidade de recursos financeiros e criação de mecanismos direcionados para garantia da qualidade do gasto público;

V processuais voltadas para os resultados - por exemplo, definição de visão de futuro para o estado, bem como de objetivos e metas, adoção de instrumentos de gestão (acordo de resultados, gestão matricial de projetos), investimento na carreira de especialistas em políticas públicas e gestão governamental (os administradores públicos) etc.; 
- desenvolvimento e evolução da política pública específica dos órgãos estudados - por exemplo, aprimoramento de indicadores, mecanismos de integração entre órgãos e entidades que compõem o sistema de defesa social e de transportes e obras, entre eles e a comunidade etc.;

v econômicas e políticas - por exemplo, aumento da capacidade de investimentos e credibilidade do estado mineiro no cenário estadual, nacional e internacional, liderança política forte (seriedade e rigor dos dirigentes da alta administração na condução das diretrizes) para direcionar as mudanças.

Embora tenha sido baixo, houve um percentual pequeno de servidores pesquisados, 5,07\%, que preferiu não se manifestar acerca das diferenças (aspectos inovadores) trazidas pelo CG em relação a gestões governamentais anteriores. Quase a totalidade do número de pesquisados - ao dar sua opinião sobre quais seriam os aspectos inovadores da política em relação a governos passados - mencionou em sua resposta mais de uma melhoria observada.

Alguns fatores importantes em relação a determinadas melhorias merecem destaque:

v verificou-se que as "melhorias tecnológicas e estruturais" foram preteridas pelos grupos de "subsecretários" das duas secretarias e pelo grupo de "idealizadores". Isso, por sua vez, confirmou o que se observou ao longo das entrevistas realizadas - que os servidores do nível operacional e tático da Seds-MG e Setop-MG, por ocuparem posições hierárquicas sujeitas aos efeitos diretos das modificações estruturais e tecnológicas, eram os atores mais propícios a reconhecer tais alterações como inovadoras;

v acredita-se que a identificação da perspectiva social ("melhorias sociais concretas e subjetivas") como uma inovação justificou-se por duas razões - a primeira disse respeito ao fato de os servidores do nível operacional e tático estabelecerem diálogos, em função da natureza de suas políticas públicas, com a sociedade e, a partir disso, terem maiores possibilidades de reconhecer as mudanças produzidas pelo CG em âmbito social. Em algumas entrevistas, ao citarem tais melhorias, os investigados fizeram reflexões nesse sentido, e a segunda razão relacionou-se a uma visão mais estratégica da política a qual, segundo seus formuladores, inovou ao oferecer mais serviços de qualidade para a sociedade, com o menor custo e maior criatividade;

- o único aspecto inovador mencionado por todos os grupos pesquisados referiu-se às "melhorias processuais voltadas para os resultados". Acredita-se, tendo como base os relatos obtidos, que a inserção da metodologia por re- 
sultados na administração pública de Minas modificou sistematicamente a rotina de trabalho dos servidores que, de um momento para outro, tiveram que agregar às suas tarefas habituais uma série de metas, submetidas a um rigoroso monitoramento;

v quanto à perspectiva inovadora de "desenvolvimento e evolução das políticas públicas" pôde-se perceber que somente os grupos executores ("diretores e técnicos" das duas secretarias, "superintendentes" da Seds-MG e "subsecretários" da Setop-MG) identificaram essa melhoria. A leitura que se fez disso foi a de que já era esperado que os atores da classe executora que lidavam constantemente com as políticas públicas de seu órgão de origem enfatizassem as mudanças produzidas na área finalística de sua secretaria;

v e, por último, entende-se que as "melhorias sociais" e as "melhorias econômicas e políticas para o estado" foram mencionadas por atores que detinham uma visão mais macro do choque de gestão, além de suas perspectivas e efeitos internos.

Esta seção apresentou análises sobre o entendimento de todas as dimensões inovadoras que caracterizaram o choque de gestão, segundo a opinião dos atores investigados das duas classes, idealizadora e executora. Antes de findá-la, no entanto, é necessário levantar dois pontos de reflexão importantes.

$\mathrm{O}$ primeiro deles relaciona-se à seguinte questão: em que medida as melhorias identificadas, pelos atores entrevistados, de fato, representaram inovações do CG, em relação a gestões governamentais anteriores? Como o cenário até o início do ano de 2003, retratado por vários servidores investigados, era muito crítico - em termos financeiros, de políticas salariais, de condições tecnológicas e estruturais de trabalho -, pode-se inferir que qualquer mínima ação, ainda que óbvia, produzida em alguns desses parâmetros poderia assumir proporções de significados e valores gigantescos. A dimensão dada a algumas melhorias, identificadas como aspectos inovadores do choque de gestão, pode ter sido superestimada e não representar, verdadeiramente, uma inovação.

O segundo ponto de reflexão envolve a seguinte pergunta: em que medida os servidores entrevistados, de fato, foram capazes de identificar as melhorias do CG, mencionadas por eles, a partir da sua própria percepção sobre a mudança - sem se deixarem influenciar pelo contexto de formação "intelectual" e profissional ao qual os mesmos, de uma forma ou de outra, estiveram submetidos? 
Além dos cursos de qualificação e capacitação, fornecidos pelos idealizadores, aos atores da classe executora, acredita-se que as rotineiras reuniões gerenciais, para acompanhamento das metas previstas nos acordos de resultados, podem ter conduzido os atores entrevistados a processos, por vezes involuntários, de interligação profunda com a política. A possibilidade de se constatar essa realidade induz a questionamentos como: quais as oportunidades geradas, os espaços de discussões abertos, para que os servidores executores, tanto da Seds como da Setop, desenvolvessem uma capacidade reflexiva de compreensão sobre o choque de gestão com certo grau de distanciamento entre o "fazer" e o "pensar", ou seja, entre o que eles executavam na prática e o que eles analiticamente percebiam sobre a política (suas diretrizes, consequências, origens, influências, vantagens e desvantagens)?

Não se tem, entretanto, a pretensão de colocar o servidor, executor da política, na posição de um agente passivo, uma vítima da classe idealizadora do choque de gestão. Até porque um dos preceitos desta pesquisa ampara-se exatamente no reconhecimento desse ator como um sujeito, com interesses e percepções individuais. Não se exclui dessa análise o entendimento de que as respostas apresentadas representaram não somente as opiniões dos servidores, sob influência do seu ambiente de trabalho; mas também as impressões deles sob interferência de seus valores, crenças e perspectivas críticas advindas da sua própria formação intelectual, cultural etc.

\section{Os aspectos inovadores do choque de gestão a partir dos preceitos teóricos}

Esta seção do artigo analisa as dimensões abordadas pelo conceito de inovação no setor público (proposto por Klering e Andrade, 2006) - estratégica, estrutural, tecnológica, humana, cultural, política e de controle - e os aspectos gerenciais e democráticos da mudança produzida em Minas Gerais, por meio do choque de gestão.

No tocante às dimensões trazidas por Klering e Andrade (2006), pôdese constatar que o CG apresentou inovações nos seguintes campos:

v estratégico - a descrição das "melhorias processuais voltadas para os resultados" evidenciou essa conclusão;

- estrutural - ao redefinir a base estrutural da administração pública mineira, adquirindo um rearranjo matricial, de forma a alinhar projetos estruturadores a resultados e finalidades organizacionais, criando instrumentos de 
desempenho, avaliação e controle das políticas públicas, os formuladores do choque de gestão realizaram uma mudança de cunho estrutural. A criação dos cargos de empreendedores públicos também representou alterações nesse sentido. Além disso, os próprios investigados identificaram as "melhorias estruturais" como fator de inovação da política;

v tecnológico - não apenas os recursos materiais foram modificados no CG, com a criação e desenvolvimento de sistemas, principalmente, vinculados às áreas de finanças, compras e pessoal, como também se investiu na perspectiva intelectual dentro do ambiente organizacional;

v controle - as "melhorias sociais" resumiram de forma clara a perspectiva de controle priorizada na mudança pretendida pelos formuladores do choque.

Quanto às demais dimensões se pôde concluir que em termos humano, cultural e político o choque de gestão não inovou. Uma análise mais cuidadosa foi exigida para a abordagem humana. Acredita-se que o modelo de gestão de Minas deu muita ênfase à questão da eficiência organizacional e não avançou no tocante à mudança de papel do indivíduo; o qual, na perspectiva humana, deixaria de ser tratado como um recurso e passaria a ser visto como uma "pessoa talentosa".

Além disso, a remuneração oferecida ao indivíduo, que deixaria de ser meramente sinônimo de incentivos financeiros para se ajustar aos desejos pessoais daquele, também não foi percebida como prioridade no CG. Embora as "melhorias pessoais concretas" tenham sido consideradas inovadoras, pelos servidores investigados, quando analisadas em função do teor e abrangência da abordagem humana da mudança, elas não representaram, de fato, inovações.

Em relação à perspectiva cultural, poucos foram os parâmetros obtidos nas entrevistas que puderam subsidiar sua análise. Contudo, apresenta-se aqui uma tentativa nesse sentido. Observando a visão dos idealizadores do CG, não se pode diagnosticar em nenhum momento das entrevistas a preocupação deles de que a política do choque fosse direcionada a uma mudança cultural.

Por outro lado, a percepção dos servidores executores, ao mencionarem as "melhorias pessoais subjetivas", deixa a entender que houve, na realidade desses atores, de acordo com seus relatos, alterações, principalmente, de valores, atitudes, hábitos e interesses. O que se concluiu disso foi o seguinte: a política do CG não definiu como finalidade produzir uma transformação cultural, mas ao longo de sua implementação, gerou efeitos que conduziram a isso, ainda que de forma incipiente.

E, por fim, considerando o fator político, pôde-se observar que foram muitas alterações provocadas na estrutura formal de órgãos e entidades, em 
função do choque de gestão; mas elas não necessariamente refletiram um ganho na questão participativa. Não se sabe até que ponto essas mudanças representaram objetivamente uma escolha de transformação política ou, simplesmente, soluções ajustáveis às necessidades demandadas pelos idealizadores do CG. Com base nas entrevistas, especialmente as realizadas com os servidores dos grupos executores, percebeu-se que a questão da participação, da comunicação e do diálogo entre as partes, parece ter ocorrido muito em função do interesse dos formuladores da política; demonstrando certa centralização das informações e da tomada de decisões por parte deles.

Uma segunda base de análise teórica se referiu às dimensões gerenciais e democráticas da mudança (abordadas por Farah, 2006). Das oito melhorias identificadas pelos atores entrevistados apenas duas poderiam ser analisadas, $a$ priori, como inovações de tendências democráticas — as "de desenvolvimento e evolução das políticas públicas" e a "social". As outras seis, claramente, representaram intervenções de âmbito gerencial nas áreas de pessoal, finanças, planejamento e resultados, tecnologia e estrutura a fim de promover a organização da máquina pública em busca de maior eficiência. Quanto aos dois possíveis fatores de inovação de cunho democratizante, pode-se verificar que:

- quando mencionaram as mudanças produzidas "no desenvolvimento e evolução das políticas públicas", os servidores entrevistados direcionaram suas argumentações, basicamente, para três tipos de melhorias - criação de indicadores que evidenciavam quantitativamente e qualitativamente as demandas sociais, instituição e aprimoramento de mecanismos de integração entre a sua secretaria e outros órgãos e entidades governamentais, bem como entre aquela e a comunidade, e entrega de serviços prestados à sociedade no prazo estipulado, durante a fase de formulação e implementação das políticas. Desses três aspectos, o primeiro e o terceiro apresentaram uma relação evidente de melhorias voltadas para a forma de gestão das políticas. Em relação ao segundo aspecto, no entanto, dúvidas foram levantadas sobre a possibilidade de as duas abordagens - a gerencial e a democrática - estarem presentes. No entanto, em todas as vezes que esse tipo de melhoria foi citado, durante as entrevistas, verificou-se que o seu significado resumiu-se apenas a alterações na forma de gerir determinados processos, com o intuito de dar à sociedade condições mais adequadas de monitorar a prestação dos mesmos, e não de fornecer a ela poder para tomar decisões na formulação ou implementação das políticas;

v a segunda possibilidade de análise sobre as melhorias que poderiam ter representado inovações democráticas no choque de gestão referiu-se às 
mudanças produzidas em âmbito social. No tocante aos instrumentos instituídos para promover maior transparência, ficou claro que essa iniciativa representou uma mudança de caráter gerencial. Já no tocante às "melhorias sociais" de cunho subjetivo não foi possível fazer uma análise das mesmas como inovações gerenciais ou democráticas, já que, embora relevantes, as respostas obtidas não forneceram parâmetros suficientes para mensurar a abrangência real da mudança.

Assim, a conclusão a que se chegou foi a de que todas as oito melhorias ou categorias de inovações do choque de gestão, identificadas pelos servidores investigados, aproximaram-se estritamente da perspectiva gerencial, tendo como principal preceito, a partir das mudanças nos processos e do foco em resultados, ampliar a eficiência com que o estado prestava seus serviços à sociedade. Quanto à dimensão democrática, a mesma não pôde ser observada com clareza em nenhum fator de inovação da política.

\section{O que os atores investigados compreendiam por inovação?}

Aqui, os atores entrevistados foram questionados sobre o que eles entendiam por inovação. As respostas dadas pelos servidores públicos levaram em consideração o contexto no qual os mesmos encontravam-se inseridos e se dividiram em nove categorias de significados, que se encontram descritas a seguir.

Inovar é mudar com capacidade de ser criativo, proativo e saber simplificar

A primeira categoria focalizou a inovação como uma mudança, de cunho individual ou institucional, na forma de agir — tornando as ações mais criativas e, ao mesmo tempo, mais simples (de forma a entregar mais para a sociedade, sem aumentar o ônus para a mesma).

\section{Inovar é crescer, com base no histórico, sem perder a qualidade}

Nesse campo de entendimento a inovação deveria ser compreendida como um processo de amadurecimento das ações governamentais - que, necessa- 
riamente, teria que levar em consideração o aprendizado advindo de outras gestões e, somente a partir disso, definir diretrizes para o desenvolvimento da administração pública em busca de qualidade.

Inovar é criar algo novo

A inovação foi explicada como a criação de novos objetivos ou de novas ações. Alguns dos entrevistados simplesmente mencionaram que inovar era criar coisas novas. Outros, porém, foram mais específicos ao definir que inovar era fazer algo novo, desde que este algo se direcionasse para ajudar, para melhorar um determinado cenário.

Inovar é mudar o que já existe na tentativa de fazer melhor

A inovação no setor público deveria ser entendida não como uma coisa nova, mas sim como uma mudança (seja de dimensões estratégicas ou operacionais - rotineiras) produzida sobre algo que já existisse; na tentativa de se obter resultados melhores.

Inovar é propor algo diferente ou uma ideia nova, que faça sentido dentro da realidade a que se propõe e se alie a uma capacidade de execução

As respostas dadas nesse sentido consideraram o fato de que não fazia sentido simplesmente propor algo novo ou diferente. Era preciso saber se o que se propunha era útil para a realidade e para o contexto em que seria aplicado. $\mathrm{E}$, por fim, além da utilidade, era necessário verificar a capacidade de se executar o que estava sendo proposto.

\section{Inovar é mudança de paradigmas}

Essa categoria identificou a inovação como, primeiramente, uma mudança na maneira de se pensar a realidade, percorrendo, a partir disso, novos caminhos e propondo-se novas alternativas de ação. 


\section{Inovar é mudar a concepção de administrar, fazendo isso de forma ousada}

Os atores que mencionaram em suas respostas essa definição sobre a temática levaram em consideração que o ato de inovar se relacionava diretamente ao desenvolvimento e à adoção de práticas modernas de gestão e de novas tecnologias.

\section{Inovar é adaptar-se à determinada realidade}

O significado de inovação foi compreendido como um processo de mudanças correntes e necessárias, com o intuito de se adaptar determinado contexto a uma realidade adversa ou inesperada. Somando-se a isso uma capacidade de mudar o tempo todo.

\section{Respostas vagas}

Nesse campo reuniram-se algumas respostas menos abrangentes, consideradas pouco significativas para serem alocadas em uma única categoria de significado, porém relevantes o suficiente para não serem desprezadas. Pode-se dizer que, aqui, foram inseridas respostas superficiais e pouco conclusivas, como a que segue: "inovação é renovação diária de coisas pequenas e grandes".

Durante a fase de análise ficou clara a preferência dos servidores pesquisados por explicar a inovação a partir de duas categorias específicas: inovar é criar algo novo; e inovar é mudar o que já existe na tentativa de fazer melhor. Esses dois conceitos representaram juntos, aproximadamente, $57 \%$ das opiniões manifestadas. O primeiro, que caracterizou a inovação como algo novo, foi o mais identificado entre os dois, com cerca de $31,42 \%$ de manifestações; seguido pelo segundo com $25,71 \%$.

A terceira e quarta respostas mais frequentes foram: propor algo diferente ou uma ideia nova, que faça sentido dentro da realidade a que se propõe e se alie a uma capacidade de execução e mudança de paradigmas. As duas foram responsáveis por quase $20 \%$ das respostas obtidas. As demais categorias foram agrupadas considerando-se um número bem menor de opiniões, pulverizado entre as mesmas.

As respostas vagas, por sua vez, que reuniram cerca de $7 \%$ das opiniões, foram apresentadas, em sua totalidade, pelos investigados dos grupos opera- 
cionais das duas secretarias (Seds-MG e Setop-MG). Parte desses atores teve dificuldades em definir o significado de inovação, não conseguindo explicitar com clareza necessária o seu conceito.

De um modo geral, os relatos analisados apresentaram um conceito de inovação que ia além do simples pensar, do renovar ou do "fazer por fazer". As opiniões manifestadas trouxeram, em seu cerne, a ideia de que o ato de inovar deveria ter uma finalidade de melhorar a coisa pública. Dessa forma, parte significativa dos conceitos mencionados carregou em si a intenção de alterar uma realidade específica, pela criação de algo novo ou da transformação de algo já existente, com o intuito de promover melhorias tanto de caráter estratégico como de cunho operacional.

Analisando a variedade de significados atribuídos à inovação conclui-se, ainda que de forma arriscada, que qualquer proposição para ser identificada como ação inovadora na gestão pública deveria levar em consideração, ao longo de sua concepção, alguns parâmetros. Tais são: a análise de experiências passadas de outras gestões governamentais a fim de, de um lado, evitar a replicação de erros e, de outro, estudar as possibilidades de adaptação de iniciativas bem-sucedidas (naqueles períodos) à realidade para a qual se pretende inovar; a capacidade individual e organizacional de ousar, ser criativo e simplificar processos de gestão e tarefas rotineiras, proporcionando assim um aumento da qualidade dos serviços ofertados; o entendimento claro sobre a utilidade e a funcionalidade da mudança pretendida para o ambiente receptor da inovação; e, por fim, a capacidade de propor ações novas (ou diferentes) e, simultaneamente, intervir nas formas de agir e pensar dos atores envolvidos com a mudança proposta.

\section{Conclusão}

Os resultados apresentados aqui, baseados em uma abordagem interpretativa (não isenta das impressões dos pesquisadores), em momento algum tiveram a finalidade, especialmente ao se tratar das percepções dos atores da classe executora, de imprimir às opiniões manifestadas um caráter generalista. Em parte, acredita-se que as entrevistas retrataram aspectos significativos do modelo de gestão mineiro, evidenciando os anseios e expectativas de determinados grupos, dispostos nas sedes dos órgãos investigados.

Ao longo da construção e consolidação deste artigo tentou-se enfatizar as impressões de cada indivíduo, tratando os dados coletados de maneira singular. Com base nisso, o que se objetivou foi trazer para o campo discur- 
sivo os aspectos-chave mencionados pelos pesquisados, com prioridade para relatos - carregados de valores, emoções e expectativas - que, acredita-se, poderiam retratar mais fidedignamente a realidade observada. Essa base construtiva serviu de sustentação para a contraposição de opiniões entre os atores das classes executora e idealizadora, a fim de perceber em que medida esses olhares se aproximavam e se distanciavam.

O diagnóstico, nesse sentido, retratou uma convergência clara entre as opiniões manifestadas pelos pesquisados, das duas classes, em relação ao choque de gestão como experiência inovadora. Como foi visto, de todos os estudados, apenas três, da classe executora, não identificaram a política de gestão mineira nessa direção; sendo que, deles, somente dois apresentaram opiniões de cunho crítico, questionando o caráter inovador do modelo.

Por outro lado, a forma como os aspectos inovadores (as melhorias) foram identificados pelos entrevistados, evidenciou uma separação clara, quase generalizada, das visões trazidas pelas classes idealizadora e executora.

Enquanto de um lado os formuladores da política mencionaram o choque de gestão a partir de uma perspectiva mais holística (visão sistêmica com mudanças consistentes, especialmente, em termos estratégicos); de outro, a grande maioria dos executores reconheceu o modelo por meio de um olhar mais restrito e pontual (limitado a pequenas alterações nos processos de rotinas ou nas políticas públicas setoriais, o qual produz, ainda que em proporções menores, melhorias expressivas).

Direcionando-se um olhar mais meticuloso para a classe dos idealizadores, foram notados alguns posicionamentos interessantes. Durante a análise das entrevistas, verificou-se que os formuladores do modelo tinham opiniões semelhantes em relação à política, verbalizando, por vezes, as mesmas expressões para descrever o choque de gestão e suas características. De um modo geral, observou-se que os atores, além de muito otimistas, estavam seguros de que o CG foi uma inovação na gestão pública mineira e de que poderia ser reconhecido como um exemplo de experiência de sucesso no setor público nacional e internacional.

Com base no conceito de inovação no setor público, que orientou este artigo, o modelo de gestão desenvolvido no estado de Minas Gerais foi inovador em relação aos seguintes aspectos: estratégico, estrutural, tecnológico e de controle. Nas demais dimensões apresentadas - a humana, a cultural e a política, o CG, embora tenha provocado alguns efeitos em direção às mesmas, não considerou, em sua concepção, as três perspectivas como finalidades prioritárias da mudança pretendida. Além disso, pôde-se 
concluir também que o choque representou uma mudança de cunho estritamente gerencial.

As principais contribuições pretendidas por esta pesquisa foram: trazer luz a algumas questões pouco abordadas como a temática "inovação no setor público"; e propor uma leitura do choque de gestão com base na percepção dos servidores públicos, elucidando as dimensões inovadoras do modelo.

Acredita-se que este artigo tenha se justificado em função de: primeiramente, o tratamento qualitativo dispensado a 70 atores da administração pública mineira, com opiniões tão diversas; depois, por tentar contrapor duas visões com graus de complexidade altos, a dos executores e a dos idealizadores do CG; e, por último, por analisar os parâmetros inovadores do choque de gestão, levando em consideração não apenas as percepções trazidas pelos servidores estudados, mas também os preceitos teóricos sobre "inovação no setor público".

Por fim, como não poderia deixar de ser, é importante sugerir o desenvolvimento de análises e estudos, direcionados para o campo da gestão pública, que favoreçam e aprimorem a discussão sobre o que vem a ser inovação no setor público; discutam sobre os aspectos inovadores do choque de gestão, mas considerando o papel dos governos locais na consolidação da proposta do modelo, bem como as limitações e os desafios do diálogo governamental entre as esferas estaduais e as municipais; e analisem os resultados obtidos pelo modelo de gestão na integralidade de suas duas fases, no tocante ao desenvolvimento temporal dos cenários econômico e social de Minas, bem como em relação aos avanços e retrocessos, observados na administração pública mineira em termos gerenciais e democráticos.

\section{Referências}

ABELL, Derek F. Duplo planejamento. HSM Management, São Paulo, n. 16, p. 106114, set./out. 1999.

BENNIS, Warren G. Organizações em mudanças. São Paulo: Atlas, 1976.

BERTERO, Carlos Osmar. Mudança organizacional e processo decisório. Revista de Administração Pública, Rio de Janeiro, v. 16, n. 2, p. 29-40, mar./abr. 1976. In: SOUZA, Wertson Brasil de. Interesse público e resistência à mudança em organizações públicas: estudo de casos em uma Secretaria de Estado. 1994. Dissertação (Mestra- 
do em Administração) - Centro de Pós-graduação e Pesquisas em Administração (Cepead), Faculdade de Ciências Econômicas (Face), Universidade Federal de Minas Gerais (UFMG), Belo Horizonte.

CAVALCANTI, Bianor Scelza. DO: considerações sobre seus objetivos, valores e processos. Revista de Administração Pública, Rio de Janeiro, v. 3, n. 2, p. 49-84, abr./jun. 1979.

FABRIS, Valério. Sessão carta ao leitor: a segunda geração do choque de gestão. Revista Gestão Minas - Construindo um novo tempo, Belo Horizonte, ano I, n. 2, p. 2, dez. 2007.

FARAH, Marta Ferreira Santos. Inovação e governo local no Brasil contemporâneo. In: JACOBI, Pedro; PINHO, José Antonio (Orgs.). Inovação no campo da gestão pública local. Novos desafios, novos patamares. Rio de Janeiro: FGV, 2006.

GUIMARÃES, Tadeu Barreto; ALMEIDA, Bernardo Tavares. Da estratégia aos resultados concretos: a experiência do governo de Minas (2003-2005). Cadernos $B D M G$, Belo Horizonte, n. 12, p. 1-64, abr. 2006.

KLERING, Luis Roque; ANDRADE, Jackeline Amantino de. Inovação na gestão pública: compreensão do conceito a partir da teoria e da prática. In: JACOBI, Pedro; PINHO, José Antonio (Orgs.). Inovação no campo da gestão pública local. Novos desafios, novos patamares. Rio de Janeiro: FGV, 2006.

MATOS, Ruy de Alencar. Para que modernizar a organização pública? Revista de Administração Pública, Rio de Janeiro, v. 22, n. 3, p. 22-26, jul./set. 1988.

MORGAN, Gareth. Imagens da organização. São Paulo: Atlas, 1996.

MOTTA, Paulo Roberto. Transformação organizacional: a teoria e a prática de inovar. Rio de Janeiro: Qualitymark, 2001.

RICHARDSON, Jarry Roberto. Pesquisa social: métodos e técnicas. 3. ed. São Paulo: Atlas, 1999.

SOUZA, Wertson Brasil de. Interesse público e resistência à mudança em organizações públicas: estudo de casos em uma Secretaria de Estado. 1994. Dissertação (Mestrado em Administração) - Centro de Pós-graduação e Pesquisas em Administração (Cepead), Faculdade de Ciências Econômicas (Face), Universidade Federal de Minas Gerais (UFMG), Belo Horizonte, 1994.

SPINK, Peter. A inovação na perspectiva dos inovadores. In: JACOBI, Pedro; PINHO, José Antonio (Orgs.). Inovação no campo da gestão pública local. Novos desafios, Novos patamares. Rio de Janeiro: FGV, 2006. 
VILHENA, Renata; MARTINS, Humberto Falcão; MARINI, Caio. In: VILHENA, Renata et al. O choque de gestão em Minas Gerais: políticas da gestão pública para o desenvolvimento. Belo Horizonte: UFMG, 2006.

WEICK, K. E.; QUINN, R. E. Organizational change and development. Annual Review of Psichology, v. 50, n. 1, p. 361-387, 1999.

WOOD JR., Thomaz. Mudança organizacional: uma introdução ao tema. In:

(Coord.). Mudança organizacional. São Paulo: Atlas, 2008. 